\title{
FILOSOFIA DA EDUCAÇÃO NA FORMAÇÃO DE PROFESSORES E ALGUNS ELEMENTOS PARA PENSAR O TERRENO DA ESCOLA
}

\author{
Mariane dos Santos Gomes; Cláudio Roberto Brocanelli. \\ Universidade Estadual Paulista Júlio Mesquita Filho - UNESP, Marília, SP. E-mail: mariane.dsg@gmail.com
}

\begin{abstract}
RESUMO
Este estudo trata de questões ligadas à Formação de Professores, tomando como referencias teóricos pensadores da Filosofia (Filosofia da Educação) e trazendo os elementos de sua reflexão para o campo escolar, favorecendo aos futuros professores uma inflexão que os torne participantes ativos do processo formativo e atuando nas discussões afins desde a sua formação inicial. Como corrente para a reflexão, é destacada a Teoria Histórico-Cultural como fator importante de consideração dos espaços formativos e da própria realidade da escola, terreno de atuação do educador. A metodologia para este estudo é a pesquisa teórico-bibliográfica, o que possibilita organizar elementos mais importantes, a nosso ver, a respeito da temática e, a partir disso, discutir possibilidades para que a formação dos educadores seja processualmente guiada por meio de reflexão filosófica da educação com fins à crítica de si e do ambiente escolar, bem como de sua prática docente.
\end{abstract}

Palavras-chave: Educação, Filosofia da Educação, Formação de Professores.

\section{PHILOSOPHY OF EDUCATION IN TEACHER TRAINING AND SOME ELEMENTS TO THINK SCHOOL} GROUND

\begin{abstract}
This study deals with issues related to teacher education, taking as theoretical references philosophers thinkers (Philosophy of Education) and bringing the elements of their reflection to the school field, favoring future teachers an inflection that makes them active participants in the training process and acting in the related discussions since their initial formation. As a current for reflection, Historical-Cultural Theory is highlighted as an important factor of consideration of the formative spaces and of the reality of the school, the educator's field of action. The methodology for this study is the theoretical-bibliographic research, which makes it possible to organize more important elements, in our view, regarding the theme and, from this, to discuss possibilities for the formation of educators to be guided by means of philosophical reflection of education in order to criticize oneself and the school environment, as well as their teaching practice.
\end{abstract}

Keywords: Education, Philosophy of Education, Teacher Training. 


\section{INTRODUÇÃO}

É possível notar questionamentos consideráveis em cursos de formação de professores que envolvam a compreensão da filosofia no campo educacional, principalmente quando pensada no âmbito da educação infantil. Nesse nível apresenta-se certo distanciamento a respeito da importância da reflexão filosófica para futuros pedagogos, o que torna a Filosofia da Educação pouco importante para alguns estudantes. Situações como esta nos levam a refletir a respeito da relevância da Filosofia da Educação e/ou da sua falta, especialmente quando a criança, mesmo na educação infantil, não é considerada um ser capaz e que carece apenas dos cuidados. Porém, nossa visão é de que ela precisa ser constituída integralmente para a emancipação em meio à cultura em que ela está inserida, seja nesse primeiro contato com a escola, seja em momentos posteriores para uma formação a mais integral possível.

Antes de ser tratada em uma área pedagógica, a Filosofia vem proporcionando reflexão a respeito da educação desde Sócrates; vem discutindo a realidade das civilizações, a constituição do homem, a sociedade e, além de tudo, refletindo o que é a educação e para quê serve, considerando que a formação do homem nem sempre esteve relacionada à escolaridade, mas aos princípios filosóficos e às possibilidades de pensamento sobre si mesmo, a vida, a sociedade e o mundo. Tomamos aqui as palavras de Saramago (2008) que ao refletir a sociedade atual direciona o pensamento à falta de Filosofia:

Acho que na sociedade actual nos falta filosofia. Filosofia como espaço, lugar, método de reflexão, que pode não ter um objectivo determinado, como a ciência, que avança para satisfazer objectivos. Falta-nos reflexão, pensar, precisamos do trabalho de pensar, e parece-me que, sem ideias, não vamos a parte nenhuma. (SARAMAGO, 2008, p.1).

Para a sociedade, seja qual for a sua realidade como posicionamento no mundo, é sumamente importante a reflexão, e que esta ressurja de seu próprio ambiente; ou seja, que os elementos que a circundam deem o que pensar a fim de que ela cresça a partir dos questionamentos que ali surgem, de forma que não copiem fórmulas, preceitos e pensamentos exteriores ou estrangeiros, mas dos próprios e verdadeiramente reais. Vários problemas enfrentados nas escolas e demais espaços não se resolvem ou não nos apontam saídas porque nos faltam a reflexão própria, o pensamento próprio e as ideias próprias. Então, a escola deve ser o espaço onde se instiga a inquirição constantemente, forma que promove a elaboração do raciocínio e a expressão do pensamento conjuntamente e de forma partilhada.

\section{METODOLOGIA}

Este estudo é desenvolvido com metodologia de caráter teórico bibliográfico, pesquisando as informações e pensamentos contidos nos referenciais e tomando-os como elementos para a reflexão acerca do espaço da escola e da importância de se obter uma reflexão no que tange à Formação de Professores, mais especificamente na disciplina Filosofia da Educação, esta como aporte para a avaliação da educação, da escola e da própria prática docente.

\section{RESULTADO}

Os posicionamentos, a organização do trabalho e a relação com o outro, podem ser consideradas, no campo educacional, e não só nele, um viés da concepção que se tem de mundo e do que é ser humano e, portanto, têm raízes filosóficas. No terreno da escola é primordial compreender a singularidade dos alunos em sala de aula e que tudo se relaciona a uma compreensão muito maior, pois "Mais do que uma inquietação teórica, explicar aquilo que caracteriza o ser humano, no que tange ao seu processo de aprendizagem, suas necessidades e suas motivações, é uma forma de compreender a própria essência humana." (RIGON; ASBAHR; MORETTI, 2010, p.13). 
Neste sentido, os autores também apontam para a compreensão de como o homem se torna homem, indicando questões que inquietam desde sempre a humanidade, a civilização, o desenvolvimento de técnicas, o trabalho, a linguagem e que tais processos estão ligadas à constituição do "ser humano".

Várias são as explicações para o processo de humanização e as ciências que os discutem: a filosofia, a antropologia, a sociologia, a biologia a psicologia, entre outras. Entretanto, consideramos que a coexistência de várias teorias explicativas para um mesmo fenômeno seja resultado, sobretudo, das diferentes bases teóricas e filosóficas que fundamentam cada uma das teorias. (RIGON; ASBAHR; MORETTI, 2010, p.15).

Vários ideais filosóficos se apresentam nas teorias estudadas nos cursos de formação de professores, e essas darão base à visão que o professor terá de sociedade, da criança na escola, da própria escola e até mesmo do 'ser professor' em meio aos desafios que tal terreno apresenta a cada dia e em cada situação particular; justamente por tais e vários motivos, é fundamental a reflexão filosófica da educação de modo que promova processualmente uma reflexão diante da realidade que cada educador irá atuar em futuro próximo, não buscando saídas por meio de modelos e receitas, mas a partir do que está aí em seu espaço.

No mesmo sentido, filósofos como Marx e Engels apontam contribuições importantes para pensar o ensino, assim como a constituição da sociedade, relação homem e trabalho e a formação do indivíduo para a sua integralidade (Marx e Engels, 2006). A trajetória histórica aponta para a contribuição de vários filósofos e pensadores que, à sua época, refletiram sobre a sociedade e fizeram suas contribuições. Partiremos das contribuições de Marx e Engels, pois não pretendemos fazer uma análise detalhada dos filósofos que contribuíram para se pensar a educação, mas sim para tratar do materialismo Histórico Dialético, nas obras de Marx, em que baseia a Teoria Histórico-Cultural. (RIGON; ASBAHR; MORETTI, 2010).

A Teoria Histórico-Cultural traz discussões que foram e vem sendo pertinentes no campo educacional, que procuram dar às crianças condições de serem sujeitos de suas ações no processo de desenvolvimento. Davidov (1988) reconhece que Vygotsky foi um psicólogo ilustre e autor fundamental da Teoria Histórico-Cultural, esta muito estudada no meio acadêmico, e que segundo Oliveira (2006) apresenta forte influências pela "categoria da atividade humana em Marx, já que é essa concepção de atividade que fundamenta toda a obra vygotskyana" (Oliveira, 2006, p.6).

São considerações importantes que alimentam a reflexão no ambiente escolar e que podem enriquecer o pensamento dos educadores, em especial, quando estes valorizam os desafios do cotidiano, o seu contexto e tudo o que é próprio daquele espaço em que estão inseridos. Reflexões que norteiam as atividades escolares e educativas são essenciais para uma concepção de professor sujeito de suas ações e que busca proporcionar o desenvolvimento qualitativo e significativo de seus alunos, instigando-os cada vez mais a aprendizados urgentes.

Tudo isso é fundamental porque os mecanismos psicológicos ligados à fala se desenvolvem gradativamente, de acordo com o meio em que a criança vive; mais tarde, se desenvolvem a percepção e a atenção. Depois dessa etapa, a percepção que era parcial, passa a compreender o todo, chegando a atingir formas complexas de percepção cognitiva. As relações da criança com os objetos e signos formam o meio principal para a distinção entre estes e os significados. Ou seja, "a relação entre o pensamento e a palavra não é uma coisa, mas um processo, um movimento contínuo de vaivém do pensamento para a palavra e vice-versa" (Vygotsky, 1991, p. 108). Tudo o que é aprendido não ocorre mecanicamente e nem porque alguém ensinou, mas porque faz parte de um processo de desenvolvimento e aprendizagem por relações entre o meio, com seus objetos e conceitos.

Outro momento importante do desenvolvimento da criança é quando ela descobre a capacidade de memória. A memória permite que relacione elementos de experiências passadas com as experiências do presente. Dentro desse panorama de desenvolvimento e aprendizagem 
estão presentes duas linhas qualitativamente diferentes: uma é formada pelo conjunto de processos elementares, de origem biológica (capacidade de andar, pegar coisas, etc.); a outra é formada pelas funções psicológicas superiores, de origem sócio-cultural (uso de instrumentos, aquisição da fala). A história da criança nasce do entrelaçamento dessas duas linhas, levando em conta que o que é biológico, é dado (é natural) e o que é cultural (costumes, valores, comportamentos, etc.), é adquirido a partir de vivências e experiências com os objetos e com as pessoas.

Para Vygotsky, o aprendizado, portanto, começa bem antes de a criança frequentar a escola. Na verdade, "aprendizado e desenvolvimento estão inter-relacionados desde o primeiro dia de vida da criança" (Vygotsky, 1998, p. 110). A função e o valor da escola, então, estão na introdução de elementos novos no aprendizado, devendo o aprendizado estar combinado de alguma maneira com o nível de desenvolvimento da criança.

Com essa ideia, Vygotsky leva em conta o nível de desenvolvimento real (que é a solução independente de problemas) e a zona de desenvolvimento proximal (que é o que define funções que ainda não amadureceram e necessitam da assistência do adulto ou qualquer outra pessoa mais capaz que possa orientar a criança). Isso quer dizer que suas capacidades e habilidades e suas inter-relações juntamente com o meio em que vive definem o desenvolvimento mental, ou seja, a interiorização das ações praticadas durante o desenvolvimento. O pensamento e a interiorização do diálogo com os demais indivíduos e o meio leva a linguagem a influenciar cada vez mais o pensamento. Podemos afirmar que existem dois grupos de funções nos indivíduos quando ainda crianças: funções que eles já dominam e funções que eles só podem pôr em ação sob a orientação de outra pessoa ou em grupos e em colaboração umas com as outras. Isso reforça que "o aprendizado humano pressupõe uma natureza social específica e um processo através do qual as crianças penetrem na vida intelectual daquelas que a cercam" (Vygotsky, 1998, p. 115).

Com a ideia de zona de desenvolvimento proximal, Vygotsky formula uma nova ideia: "a de que o 'bom aprendizado' é somente aquele que se adianta ao desenvolvimento" (Vygotsky, 1998, p. 115). Assim, aprendizado não é desenvolvimento, mas o aprendizado adequadamente organizado resulta em desenvolvimento mental e põe em movimento os processos de desenvolvimento que, de outra forma, não aconteceriam. Conclui-se aqui que o aprendizado escolar é um aspecto essencial e necessário do e para o desenvolvimento das funções psicológicas e intelectuais. $O$ aprendizado e o desenvolvimento seguem o mesmo caminho, mas o aprendizado está à frente, ou seja, o desenvolvimento depende do aprendizado.

Um outro aspecto do aprendizado pensado por Vygotsky é o seguinte:

"embora o aprendizado esteja diretamente relacionado ao curso do desenvolvimento da criança, os dois nunca são realizados em igual medida ou em paralelo. 0 desenvolvimento nas crianças nunca acompanha o aprendizado escolar da mesma maneira como uma sombra acompanha o objeto que a projeta. Na realidade, existem relações dinâmicas altamente complexas entre os processos de desenvolvimento e de aprendizado, as quais não podem ser englobadas por uma formulação hipotética imutável" (Vygotsky, 1998, p. 119).

A partir desses dois aspectos da aprendizagem, podemos afirmar que o desenvolvimento depende não somente do que é aprendido, mas também das mudanças que ocorrem em cada indivíduo de acordo com a passagem de um estágio para outro em relações dinâmicas. Ou seja, são inúmeros os fatores internos e externos que direcionam e determinam o desenvolvimento de cada indivíduo.

A metodologia de Vygotsky privilegia a mudança, considerando o homem como participante ativo e vigoroso de sua própria existência. Em cada estágio do desenvolvimento a criança adquire meios para intervir de forma competente no seu mundo e em si mesma. Por fim, o estudo de Vygotsky é uma tentativa de afirmar que a atividade humana tem consequências 
voltadas para a transformação da natureza e da sociedade. Seus estudos têm importância justamente por valorizar o desenvolvimento da criança a partir do meio em que ela vive, ou seja, por considerar o desenvolvimento a partir da história e cultura de forma crescente e constante. Para esses dois autores, não há estágios determinados, sendo possível avançar sempre mais, tendo sempre o cuidado para não adiantar bruscamente as idades, mas levando a criança a aprender e descobrir o maior número de conceitos e idéias possíveis dentro dos limites de suas capacidades.

A partir do pensamento de Vygotsky, entendemos que o pensar é a interiorização da fala e que o comportamento recíproco de grupo em discussão desempenha papel importante no aprender a pensar. Assim como o pensar se desenvolve de acordo com o aprimoramento da fala, também a fala enquanto discurso se desenvolve conforme se aprende a pensar. $O$ aperfeiçoamento tanto da fala como do pensar depende de seu desenvolvimento a partir do meio que em o indivíduo está inserido. A origem de nosso pensamento pode ser explicada a partir das atividades externas, abertas, principalmente no que diz respeito às atividades linguísticas. Essas atividades, primordialmente sociais, passam a ser representadas mentalmente por um processo de interiorização, ou seja, os pensamentos e suas relações correspondem com nossas atividades no mundo.

Um exemplo que ilustra essa ideia relacionada à educação é de uma sala de aula onde o professor é quem sempre domina a discussão, onde ele pergunta e já oferece a resposta pronta sem permitir a participação dos alunos, obrigando-os a somente copiarem as informações; é bem provável que o comportamento desses indivíduos continuará no mesmo padrão durante todos os anos escolares, ocorrendo pouco avanço. Numa sala de aula como essa não haverá desenvolvimento do pensamento e nem aperfeiçoamento do raciocínio, mas predominará uma letargia cognitiva.

Com isso, é precioso fazer da sala de aula uma comunidade reflexiva, participante e interrelacional por meio de um diálogo vigoroso e razoável, onde não haja grandes distâncias entre professor e aluno, mas que esse diálogo se amplie entre todos os membros da mesma classe. Ao mesmo tempo, as intervenções sofridas durante a educação, no caso intervenções pedagógicas, estão diretamente relacionadas com o desenvolvimento resultante da mente da criança, e as intervenções e estímulos pedagógicos é que vão definir a atividade e desenvolvimento do raciocínio habilidoso.

\section{DISCUSSÃO}

Temos, constantemente, alterações legais que interferem o campo da filosofia na educação básica, e que transitam entre sua obrigatoriedade ou não. Vamos partir do que aparenta estar distante. Tivemos, em 15 de maio de 2009, a resolução № 1 que "Dispõe sobre a implementação da Filosofia e da Sociologia no currículo do ensino médio da edição da Lei no 11.684/2008, que alterou a Lei no 9.394/1996, de Diretrizes e Bases da Educação Nacional (LDB)." (BRASIL, 2009, p. 1) e recentemente temos no cenário educacional brasileiro a BNCC (Base Nacional Comum Curricular) que acabam, em nossa interpretação, por colocar a filosofia a prova, em segundo plano ou plano nenhum. Não a elimina, mas não a considera obrigatória deixando uma lacuna quanto ao futuro da unidade curricular de filosofia. Portanto, é fundamental que, não havendo a presença da Filosofia na escola desde o início, que ao menos os educadores tenham um contato com a Filosofia, isso por meio da Filosofia da Educação, motivando a reflexão a respeito da função e da prática docente e do próprio terreno da escola, sendo ela espaço oportuno de formação que valorize as individualidades, as diferenças e as potencialidades das crianças. Como o mais comum é a desconsideração das ações dos estudantes, queremos, aqui, possibilitar a reflexão do leitor de forma que valorize tais espaços, especialmente a relação entre o eu há de 
real e o que pode haver de proximal, bem como a valorização do ambiente a fim de promover o aprendizado que se adiante ao desenvolvimento.

\section{CONCLUSÃO}

Por fim, sugerimos nesta reflexão que os profissionais das várias áreas tenham em seu componente curricular a compreensão filosófica. Defendemos que a formação inicial influencia fortemente na atuação do profissional da educação. Como a Filosofia não está presente na escola obrigatoriamente fica a cargo do curso de formação de professores dar bases filosóficas da educação aos estudantes que por muitas vezes conhecem minimamente a área do conhecimento que é tão relevante para a compreensão do sujeito e do processo de humanização, da cultura e da história, bem como do espaço que frequentam e que podem favorecer de maneira muito positiva o desenvolvimento das crianças. Vemos que esse contexto é incompreendido nos cursos de formação de professores ou tardam em dar significado aos alunos de graduação; isso ocorre não devido à falha de um ou outro professor, mas por haver um sistema que proporciona amarras ao pensamento, impedindo a reflexão crítica. Assim, para a atuação na educação infantil e nos anos iniciais do Ensino Fundamental, é mister visitar os fundamentos da educação com bases filosóficas com fins à compreensão dos contextos, vidas e desafios que ali se passam.

\section{REFERÊNCIAS}

BRASIL, Ministério Da Educação Conselho Nacional De Educação Câmara De Educação Básica. Resolução no 1, de 15 de maio de 2009. Publicada no DOU de 18/5/2009, Seção 1, p. 25. Disponível em: < http://portal.mec.gov.br/dmdocuments/resolucao cne ceb001 2009.pdf> Acesso em: 24 jul. 18.

DAVYDOV, V. V. Problemas do Ensino Desenvolvimental - A Experiência da Pesquisa Teórica e Experimental na Psicologia. Tradução: José Carlos Libâneo e Raquel A. M. da Madeira Freitas. 1988.

OLIVEIRA, Betty Antunes de. Fundamentos filosóficos marxistas da obra vigotskiana: a questão da categoria de atividade e algumas implicações para o trabalho educativo. In: MENDONÇA. Sueli Guadalupe de Lima; MILLER, Stela (Orgs.).Vigotski e a escola atual: fundamentos teóricos e implicações pedagógicas. Araraquara, SP: Junqueira \& Marin, 2006. p. 3-26.

RIGON, Algacir Jose; ASBAHR, Flávia da Silva Ferreira; MORETTI, Vanessa Dias. Sobre o processo de humanização. In: MOURA, Manoel Oriosvaldo.(Org.). A atividade pedagógica na teoria histórico cultural. Brasília: Liber livro, 2010.

SARAMAGO, José de Souza. Pensar, pensar. Expresso. Portugal (entrevista), 11 de Outubro de 2008. Disponível em: <http://caderno.josesaramago.org/69370.html> Acesso em: 01 jun. 2018.

VYGOTSKY, L. S. Pensamento e linguagem. Coleção Psicologia e Pedagogia. Tradução de Jeferson Luiz Camargo. 3a. Edição. São Paulo: Martins Fontes, 1991.

- A formação social da mente: o desenvolvimento dos processos psicológicos superiores. São Paulo: Martins Fontes, 1998. 